\title{
Relationship between Poverty and Child Abuse among Secondary School Students in South West Nigeria
}

\author{
Odu Bimbola Kemi, Alokan Funmilola Bosede \\ Faculty of Education, University of Ado-Ekiti, Nigeria
}

\begin{abstract}
This study investigated the relationship between poverty and child abuse among public secondary school students in South West Nigeria. A descriptive research design of exploratory type was adopted for the study. A total of 1.440 public secondary school students in 36 schools from 9 local government areas in 3 Southwestern states of Nigeria were sampled for this study. Out of these students, 695 students were found to be abused and their responses formed the data that were analyzed for this study. A self constructed questionnaire titled Child Abuse Questionnaire (CAQ) was administered on the students after validation. The instrument has construct validity co-efficient of 0.756 and $a$ reliability co-efficient of 0.83 . The statistical technique that was used to analyse the data collected was Pearson Product Moment Correlation.

The result of the analysis showed that there was a significant relationship between poverty and child abuse among these secondary school students. Based on this finding, it was recommended that free, universal and compulsory education should be made available to all Nigerian children up to secondary school level to alleviate the burden of povertystricken parents

It was recommended that local agencies and NGOs should focus on income generating activities and micro-credit for parents. Among others, it was also recommended that counsellors should be on the look-out to identify and help the abused students.
\end{abstract}

\section{Introduction}

Child abuse consists of any act, or failure to act, that endangers a child's physical or emotional health and development. Child abusers inflict physical, sexual and emotional trauma on defenceless children every day. The scars can be deep and long-lasting. Unfortunately, the more subtle forms of child abuse such as neglect and emotional abuse can be even more traumatizing than violent physical abuse. According to Owuamanam et al [14], the African Charter on the rights and welfare of the child recognizes that the child in any African setting occupies a unique and privilege position and that the child should grow up in a complete state of wellbeing to be provided by the family for full and harmonious development of his personality. The requirements embedded for a complete state of wellbeing are basic amenities, parental responsibilities in all dimensions, freedom to belong, adequate shelter, personal growth, autonomy, purpose in life, environmental mastery, and positive relations with others. Poverty has made it very difficult for many African children to achieve all these.

Poverty is one of the major problems facing families in Africa. Poverty creates an environment that is very damaging to the development of children in every way, and affects their mental, physical, spiritual and emotional well-being. It threatens the children's rights to education, good nutrition, stable health, survival, protection from exploitation and harm and also exposes them to all forms of abuses [14].

There are various types of child abuse. There are physical abuse, sexual abuse, emotional abuse and neglect. Physical child abuse is an injury resulting from physical aggression. Even if the injury was not intended, the act is considered physical abuse. Sexual child abuse is a sexual act between an adult a child. Emotional child abuse is any attitude, behaviour, or failure to act that interferes with a child's mental health social development. It can range from a simple verbal insult to an extreme form of punishment. Neglect is a very common type of child abuse. According to Child Welfare Information Gateway [6] more children suffer from neglect than from physical and sexual abuse combined. Yet victims are not often identified, primarily because neglect is a type of child abuse that is an act of omission, of not doing something.

Child abuse occurs in many forms and across all socio-economic groups. It is a known fact that some parents who live in poverty do not maltreat their children but research shows that children who grow up in poverty can be more vulnerable to some forms of maltreatment, particularly neglect and physical abuse. They also have an increased risk of adverse experiences and negative outcomes, both in the short and long term. These outcomes include poor health (physical and mental), death from illness or accident, 
educational disadvantage and disaffection, unemployment, poverty during adulthood, criminalization for anti-social behavior or offending, as well as becoming victims of crime. Children who experience both poverty and maltreatment are doubly disadvantaged because the experience of maltreatment may in turn further undermine life chances in the long term (NSPCC [13]).

There is no single definition of poverty but the two most commonly used concepts are absolute poverty and relative poverty. Absolute poverty refers to a state in which income is insufficient to prove the basic needs required to sustain life (that is, food and shelter). Relative poverty defines income or resources in relation to the average, and recognizes that human needs are socially derived and therefore vary according to social contexts and the ability (or inability) to participate in the social norms of one's society. Townsend [16] considers that individuals, families and groups are in relative poverty "if they lack the resources to obtain the types of diet, participate in the activities and have the living conditions and amenities which are customary or at least widely encouraged or approved in the society to which they belong.

According to Cawson [5], the most comprehensive and methodologically sophisticated prevalence study conducted in the UK is the NSPCC's Child Maltreatment in the Family. The research comprised of a random probability sample of 2,869 young people aged 18-24, who were interviewed about family life in childhood, their parents' and other people's behaviour towards them, their own wellbeing and views on the treatment of children. In this study, about one-third of all respondents agreed with the statement that "there were always a lot of worries about shortage of money" in their families when they were children, but this proportion rose to 65 percent among those who had experienced serious physical abuse or serious neglect, and 71 percent of those who had experienced emotional maltreatment- no social class trends were identified for emotional maltreatment using other indicators. This study confirmed the association between socio-economic status, financial problems in the family and parental child abuse, though it is much stronger with physical and emotional abuse and absence of physical care than with either sexual abuse outside the family or absence of supervision (Cawson[5]).

The findings also showed that compared to young professional respondents, young people working in semi-skilled or unskilled jobs were three times more likely to have suffered serious physical abuse, and ten times more likely to have experienced a serious absence of care in childhood; compared to respondents in higher education, they were twice as likely to have experienced such neglect (Hopper et al [12]).
A major cause of child abuse can be traced to poverty. According to eNote.com [10] there is now overwhelming evidence of a strong relationship between poverty and child abuse. The great majority of families to whom child abuse have been attributed live in poverty or near-poverty circumstance.

Also Gelles [11] and Drake, Brett and Pandey [8] pointed that there is strong evidence that poverty is associated with child abuse. Xierali [18] conducted a study in eight counties in Cincinnati and Northern Kentucky area of United States of America. He found out that child abuse counts strongly correlate with the poverty measurements; and that areas with poverty concentration tend to have higher child abuse counts.

Drucker [9] also concluded, in his research that although child abuse occurs across the socioeconomic spectrum, evidence shows that poor families are more likely than those with more economic resources to be identified and labeled as maltreating.

Various features of child abuse negate the United Nations convention and O.A.U charter on Right of child in 1989 [17]. The basic principles of children's rights among others are: every child has the right to live and develop; every child is entitled to adequate rest and recreation; every child is entitled to receive basic education and good health care.

The abused children are costly investment deficits for the society. This is because they arc prone to high incidence of personality disorder and lack social skills for dealing with others (Aluko [3]). Some abused children often repeat the vicious cycle by becoming abusive parents. This study is therefore based on finding the relationship between poverty and child abuse, in Nigeria.

\section{Research Rationale}

Every day, there are children living hungry, neglected, sexually exploited and fearful. An abusive environment is certainly no way for a child to growup. Children have the right to safe and maturing environment.

In our society, one sees children engaged in pettytrading and street begging; while some hawk for their parents and guardians when they should be laying a solid foundation for their future. One also sees cases of child prostitution to get money. Parents leave their children at home uncatered for and run after money making.

The average school teacher today has on his hands a crisis resulting from parent's abdication of their responsibilities and many teachers believe this has adversely affected character and output of students (Ale, [2]). There are cases of deprivation of adequate nutrition. There is also exploitation of children as aids by handicapped adults during street begging. 
In the era of high rates of parental poverty, unemployment, inflation and social exclusion, parental care of several children in Nigeria is likely to fall below expectation; not necessarily because their parents are illiterate, ignorant, abusive or neglectful but largely because-of inequality of access to child care resources. When parents are unable to adequately meet the welfare of their children, one expects that family and childcare institution should intervene. Unfortunately, the childcare institutions in the country are incapacitated by poverty.

According to Adeniran [1], abused children grow up as callous, insensitive adults with varied repercussions for families and society. They become cognitively deficient and create various cadres of street children. To this end, a crucial research hypothesis was raised.

\section{Hypothesis}

There is no significant relationship between poverty and child abuse among public secondary school students in South West Nigeria.

\section{Methodology}

The researchers used descriptive research design of exploratory type. The plan of study involved the use of questionnaire to collect data in order to test the hypothesis raised in the study. The target population for this study was made up of public secondary school students in South West Nigeria, who were within the age range of 9-18 years. Multistage random sampling was used in drawing out the sample.

Since the study is on South West Nigeria as a whole, the researchers recognized the states, local governments and schools. The researchers therefore selected the sample in stages.

Out of the six states in South West Nigeria, three were chosen. Also, out of the local government areas in each of the three states, three were selected by simple random sampling technique. In each local government, four secondary schools were selected by simple random sampling. In each school, 40 students were selected. Copies of questionnaire were given out to 1440 students in 36 schools. Exploratory method was then used. Out of these questionnaires, the researchers brought out those of abused students; that is, those who scored 200 and above out of the 300 score obtainable. The respondents that scored 200 and above were 695 in number. Their questionnaires were used in data analysis.

A self-designed questionnaire called Child Abuse Questionnaire (CAQ) was used for this study. Part A was designed to collect information on background characteristic of respondents; part B consisted 28 items which elicited students' responses on child labour, sexual abuse, physical abuse and child neglect; while part C consisted 32 items which brought out such psychosocial factors as poverty, broken home, death of parents, psychological disorder and family interaction.

The methods used in validating the instrument were face, content and construct validities. For face validation, the experts determined at face level the appropriateness of the instrument in measuring what was being studied, to ascertain if the instruments elicit the intended responses on child abuse and the psychosocial factors.

Expert judgments were used in determining the content validity. The experts checked the extent to which the items were representative of content, practices and factors specified by the theoretical concept being measured. The scores of the test administration on 30 abused secondary students were correlated with that of Child Abuse and Neglect Test (CANT) using Pearson Product Moment Correlation, a correlation coefficient of 0.756 was obtained. This indicated that the research instrument used (CAQ) clearly measures the same construct with CANT.

A reliability test was also carried out on 20 abused secondary school students using Pearson Product Moment Correlation. A reliability coefficient of 0.83 was obtained. On the basis of these psychometric properties, the instrument was found to be suitable for data collection. Copies of the questionnaire were distributed by the researchers and the school counsellors to a sample of 1,440 students in 36 schools. Researchers' presence during administration enhanced better understanding of the items in the instrument. Copies of the questionnaire were collected back immediately after completion by the researchers.

The data generated were subjected to Pearson Product Moment Correlation analysis. The hypothesis was tested at 0.05 level of significance.

\section{Test of Hypothesis}

$\mathrm{H}_{\mathrm{o}}$ : There is no significant relationship between poverty and child abuse among public secondary school students in South West Nigeria. Table shows the result of the analysis.

Table 1. Pearson Product Moment Correlation Summary on Poverty and Child Abuse

\begin{tabular}{|l|l|l|l|l|l|}
\hline Variable & $\mathrm{N}$ & $\mathrm{X}$ & $\mathrm{SD}$ & rcal & rtable \\
\hline Poverty & 695 & 20.96 & 4.69 & 0.595 & 0.195 \\
\hline $\begin{array}{l}\text { Child } \\
\text { Abuse }\end{array}$ & 695 & 90.25 & 12.42 & & \\
\hline
\end{tabular}

P- 0.05 
The table shows that the mean total score of poverty is 20.96 with standard deviation of 4.69 while the mean total score of child abuse is 90.25 with standard deviation of 12.42 . Since r-calculated (0.595) is greater than r-table (0.195). The hypothesis was rejected. This indicated that there is a significant relationship between poverty and child abuse.

The probable explanation for this could be that poverty makes it difficult for parents to cater for their children; hence they force the children to do some odd jobs to make ends meet and invariably become breadwinner of the family. Conversely Spinetta and Rigler [15] cautioned against interpreting the relationship between poverty and child abuse. They explained that deprived families do not abuse their children. In a similar vein Butler and Burton [4] disputed the claim and maintained that child abuse is more common in the impoverished families; this is in line with findings of this study. De Leonardi [7] and Gelles [11] also found that poor families are more likely than those with more economic resources to be identified and labelled as maltreating. NSPCC [13], in its studies, also highlighted the link between poverty and some forms of child maltreatment, especially neglect, emotional and physical abuse. Hence, poverty is a predictor of child abuse

\section{Conclusion}

Evidence from the study has led the researchers to conclude that many secondary school students in South West Nigeria experience child abuse and one of the major causes of child abuse is poverty.

\section{Recommendations}

Based on the findings of the study, the following recommendations were made:

1. Free, universal and compulsory education should be made available to all Nigerian children up to secondary school level. This will alleviate the burden of poverty stricken parents and guardians.

2. Considering that some aspects of child abuse are rooted in economic difficulties, it is recommended that local agencies and NGOs should focus on income generating activities and microcredit for parents.

3. Due to poverty, many children do not have enough to eat. It is therefore recommended that school meals should be introduced and considered an important contribution by government to improvement of nutritional standard of the child in this period of profound economic crisis.

4. Counsellors should be on the look-out to identity and render help to abused students.

\section{References}

[1] Adeniran, K. (2003). Child Abuse and Neglect among Junior Secondary School students in Ibarapa area of Oyo Slate Nigeria. A dissertation submitted to the department of Health Promotion and Education. College of Medicine, University of Ibadan.

[2] Ale, A. (2007 March 17). Where have the Parents gone?: Family experts decry neglect at the home front. Saturday. Punch, p.3.

[3] Aluko, J.A (1996). Child Abuse, Neglect and Prevention. A paper presented at African Network for the Prevention and Protection Against Child Abuse and Neglect Conference in Jos.

[4] Butler, V.R. and Burton. L.M. (1990). Rethinking teenage childbearing: Is sexual abuse a missing link? Family Relations 39(2): 73-80.

[5]Cawson, P. (2002). Child Maltreatment in the Family: The Experience of a National Sample of Young People. London: NSPCC.

[6] Child Welfare Information Gateway (2007). U S. Department of Health and Human Services. Retrieved on $31 / 8 / 2007$

[7] De Leonardi, J.W. (1993). Families in poverty and chronic neglect of children. Families in Society, 557-562.

[8] Drake, Brett and Shanta Pandey (1996). Understanding the relationship between neighborhood poverty and specific types of child maltreatment. Child Abuse and Neglect. 20 (11): 1003-1018.

[9] Drucker. P.M. (1997). The Consequences of Poverty and Child Maltreatment on IQ Scores. The Vincentia Center for Church and Society.

[10] eNotes Viewpoints (2008). Poverty Causes Child Abuse. eNotescom. http ://www.enotes.com

[11] Gelles, R.J. (1992). Poverty and violence toward children. American Behavioural Scientist. 35 (3): 258274.

[12]Hopper, C.A. et al (2007). Living with Hardship 24/7: The Diverse Experiences of Families in Poverty in England. York: The Frank Buttle Trust.

[13]NSPCC (2008). Poverty and Child Maltreatment. Child Protection Research Briefing. The Online Child Protection Resource. www.nspcc.org. uk/inform.

[14] Owuamanam, D.O, Owuamanam, T.O, Akinleye, G.A, Odu, B.K(2008). Introduction to Psychology of Education. Vintage publishers, Ibadan, Nigeria.

[15] Spinetta, J. Rigler, S. (1992). The child-abusing parent: A psychological review. Psychological Bulletin. 77:296-304. 
[16]Townsend, P. (1979). Poverty in the United Kingdom: A Survey of Household Resources and Standards of Living. Harmondsworth: Penguin Books.

[17] United Nation Children's Fund (1989). United Nations Convention on the Right of the child and organization of African Unity Charter. Lagos Country Office.

[18] Xierali, I. (2006). Poverty and Child Abuse Counts. University of Cincinnati. United State of America. 